\title{
ANTHROPOMETRY AND BLOOD HAEMOGLOBIN STATUS OF WOMEN IN MAKWANPUR DISTRICT, NEPAL
}

\section{ABSTRACT}

\author{
Manandhar $\mathbf{B}^{1}$, Osrin $\mathrm{D}^{2}$, Shrestha $\mathbf{B} \mathbf{P}^{1}$ \\ Shrestha J R ${ }^{1}$, Manandhar D $S^{1}$, Costello A $\mathrm{M}^{2}$
}

\begin{abstract}
Background
The nutritional situation of women in Nepal remains precarious. Low energy, protein and micronutrient intakes contribute to high levels of stunting and anaemia throughout the life cycle. This suboptimal nutritional status contributes to high prevalences of low birth weight and death in early infancy. As background information for an ongoing study of perinatal health interventions in 24 Village Development Committees (VDCs) of Makwanpur District, a descriptive study of nutritional status and anaemia in a sample of women was carried out.
\end{abstract}

\section{Objectives}

To measure weight, height, mid-upper arm circumference (MUAC) and blood haemoglobin in non-pregnant married women of reproductive age.

\section{Methods}

Participants aged between 15 and 49 years were recruited at 12 sites in five VDCs. Personal details were collected in each case, after which height, weight, mid-upper arm circumference (MUAC) and blood haemoglobin level were measured.

\section{Results}

Results are available for 500 women. Mean height was $149.9 \mathrm{~cm}(95 \%$ confidence interval for mean $149.5-150.4 \mathrm{~cm})$; mean weight was $45.5 \mathrm{~kg}(95 \%$ CI 44.9 - $46.1 \mathrm{~kg})$; mean Body Mass Index (BMI) was $20.2 \mathrm{~kg} / \mathrm{m}^{2}\left(95 \%\right.$ CI $\left.20.0-20.4 \mathrm{~kg} / \mathrm{m}^{2}\right)$; mean MUAC was $23.47 \mathrm{~cm}$ (95\% CI 23.2 - $23.7 \mathrm{~cm})$. Overall, $27.8 \%$ (95\% CI 24.1 - 32.2\%) of women showed evidence of Chronic Energy Deficiency (CED) on the basis of BMI, and 51.5\% (95\% CI 47.0 $56.0 \%$ ) on the basis of MUAC. There were no significant differences in BMI or MUAC between either ethnic or age groups. $35.3 \%$ of women were anaemic $(95 \%$ CI $31.1-39.7 \%)$, one percent severely so. There were no significant differences in prevalence between ethnic groups, but there was some evidence of an increase in anaemia prevalence with age.

\section{Conclusions}

CED and anaemia appear common in Makwanpur District. As part of a package to improve newborn infant outcome, access to and uptake of haematinics during pregnancy should be beneficial. Community level intervention needs to attempt to address the issue of food intake in young girls and women before improvements in nutritional status are possible.

\section{Key Words: Anaemia, anthropometry, nutritional status, Nepal.}

1. Mother Infant Research Activities, Kathmandu.

2. International Perinatal Care Unit, Institute of Child Health, University of London.

Address for correspondence : $\quad$ Dr. D. S. Manandhar, MIRA

GPO Box: 921, Kathmandu, Nepal. 


\section{INTRODUCTION}

The nutritional situation of women in Nepal remains precarious. Low energy, protein and micronutrient intakes contribute to high levels of stunting and anaemia throughout the life cycle. This suboptimal nutritional status contributes to high prevalences of low birth weight and death in early infancy. Nepal's current neonatal and infant mortality rates are 50 and 79 per thousand respectively. The estimated maternal mortality ratio is 539 per hundred thousand livebirths. ${ }^{1}$

Mother Infant Research Activities (MIRA), in collaboration with the Institute of Child Health, London, are presently conducting a study on the impact of a community-based participatory intervention to improve essential newborn care (ENC) in rural Nepal. The study is a cluster randomised controlled trial involving 12 pairs of Village Development Committees (VDCs) in Makwanpur District. The first phase of the study involves community entry, qualitative studies on the ethnography of childbirth and neonatal illness and a household survey to enumerate married women of reproductive age (MWRA).

As part of this phase, and to broaden our understanding of the background to the situation and potential routes of intervention, we undertook a descriptive study of nutritional status and anaemia in a sample of women from the study area.

\section{OBJECTIVES}

To measure weight, height, mid-upper arm circumference (MUAC) and blood haemoglobin in MWRA, as a means of assessing risk for maternal and neonatal outcomes.

\section{METHODS}

\section{SETTING}

Makwanpur District occupies 2426 sq km and lies to the south of Kathmandu in the Central Region and the Narayani Zone. It has a population of 376 342 (1998 projection from 1991 census.) $)^{2}$ The district has a Human Development Index of 0.309 and a Gender Sensitive Development Index of 0.231 and includes both hill and terai areas. Literacy runs at about $34 \% .^{2}$ The district centre is Hetauda, where the MIRA field office is located. The ethnic composition of the district is mixed: District Development Committee records suggest that the largest group are Tamang (46\%), followed by Brahmin/Chhetri (25\%), Magar (5\%) and Newar $(8 \%)$. The major occupation is agriculture, in which the great majority of residents are engaged.

\section{SAMPLE SIZE}

A sample size of 500 was selected on the basis of confidence intervals for the proportion of women who were found to be anaemic. The sample was stratified by ethnic group as follows: Tamang, Brahmin/Chhetri, Magar, Newar, other.

\section{ENROLMENT}

The study was carried out at 12 sites in 5 VDCs. Sites were selected by the Project Manager and local Surveillance Supervisor after discussion with local Female Community Health Volunteers (FCHVs). Sites reflected concentrations of possible participants, for example schools, health posts and individual households. The principal investigator visited each site, at which local women had 
gathered after preinformation. The investigator conducted a health education session about nutrition in general and anaemia in particular, framed in the local context and using locally available foods. The aims and procedures of the study were explained and discussed, and verbal consent was obtained from each woman interested in participating.

Inclusion criteria were: age 15 - 49 completed years; married status; non-pregnant status; at least 45 days post delivery if recently pregnant; healthy or with minor illness. Minor illnesses that were included in the final sample were cough and cold, menstrual irregularity associated with family planning methods, headache, and aches and pains. Malaria is uncommon in Makwanpur District.

Exclusion criteria were: below or above the age range; unmarried status; pregnancy; less than 45 days post delivery if recently pregnant; serious illness at the time of the study. For each woman, a questionnaire was completed containing the following fields: name, age, educational level, ethnic group, occupation, husband's occupation, parity, use of family planning, current serious illness, menstrual duration and degree of blood loss.

Height was measured in centimetres $(\mathrm{cm})$ with a freestanding aluminium stadiometer accurate to 1 mm (CMS Weighing Equipment Ltd, London, UK). Weight was measured in kilogrammes $(\mathrm{kg})$ on an electronic adult scale accurate to $100 \mathrm{~g}$ (Soehnle, Germany). MUAC was measured in $\mathrm{cm}$ at the mid-point between olecranon and acromion process, with a plastic measuring tape accurate to $1 \mathrm{~mm}$. Blood haemoglobin was measured in grams per decilitre $(\mathrm{g} / \mathrm{dL})$ in a fingerprick sample (Unilet Superlite, Owen Mumford, Oxford, UK) with a BHaemoglobin photometer accurate to $100 \mathrm{mg} / \mathrm{dL}$ (HemoCue AB, Angelholm, Sweden) that had been calibrated prior to use in the study.

\section{DEFINITIONS}

Two key anthropometric summary variables were employed in the study. Body Mass Index (BMI) was computed as weight in kilogrammes $(\mathrm{kg})$ divided by the square of height in metres (m). Low BMI is presumed to reflect Chronic Energy Deficiency (CED) $)^{3,4}$ and BMI has been classified by the WHO for non-pregnant adults as follows: greater than $18.5 \mathrm{~kg} / \mathrm{m}^{2}$ corresponds with normality; $17.0-18.49 \mathrm{~kg} / \mathrm{m}^{2}$ corresponds with grade $1 \mathrm{CED}$, or mild thinness; 16.0 - $16.99 \mathrm{~kg}$ / $\mathrm{m}^{2}$ corresponds with grade $2 \mathrm{CED}$, or moderate thinness; less than $16.0 \mathrm{~kg} / \mathrm{m}^{2}$ corresponds with grade $3 \mathrm{CED}$, or severe thinness. ${ }^{5}$

MUAC represents a combination of bone, muscle and fat, and reflects tissue reserves of energy and protein. It has been similarly classified (on the basis of values that corresponded with BMI cut-off values in samples from eight developing countries) for non-pregnant women as follows: greater than 23.3 cm corresponds with normality; $22.2-23.2 \mathrm{~cm}$ corresponds with grade 1 CED, or mild thinness; $21.4 \mathrm{~cm}-22.1 \mathrm{~cm}$ corresponds with grade $2 \mathrm{CED}$, or moderate thinness; less than $21.4 \mathrm{~cm}$ corresponds with grade $3 \mathrm{CED}$, or severe thinness. ${ }^{5}$ Anaemia was categorised according to current guidelines, as: less than $7 \mathrm{~g} / \mathrm{dL}$ implies severe anaemia; 7 - $11.9 \mathrm{~g} / \mathrm{dL}$ implies moderate anaemia; greater than $11.9 \mathrm{~g} / \mathrm{dL}$ implies normality.

\section{RESULTS}

Results are available for 500 women. Two women declined the fingerprick for blood haemoglobin measurement; one of these also declined MUAC measurement. The ethnic group breakdown was as follows: the largest group were Tamang (191), followed by Magar (99), Brahmin/Chhetri (80), Newar (55) and a composite group of other women who came from a range of ethnic groups, the largest 
Table 1 : Height, weight, BMI, MUAC and haemoglobin for the sample, by ethnic group and age group.

\begin{tabular}{|c|c|c|c|c|c|c|c|c|c|c|c|}
\hline & & \multicolumn{5}{|c|}{ Ethnic group } & \multicolumn{4}{|c|}{ Age group } & \multirow[t]{2}{*}{ All groups } \\
\hline & & Tamang & Magar & $\begin{array}{c}\text { Brahmin } \\
\text { Chhetri }\end{array}$ & Newar & Other & $<20$ & 20-29 & 30-39 & $40-$ & \\
\hline & $\mathbf{n}$ & 191 & 99 & 80 & 55 & 75 & 29 & 214 & 173 & 81 & 500 \\
\hline \multirow{3}{*}{$\begin{array}{l}\text { Height } \\
(\mathrm{cm})\end{array}$} & mean & 149.60 & 149.13 & 151.04 & 152.05 & 149.51 & 149.60 & 150.24 & 150.21 & 149.09 & 149.94 \\
\hline & sd & 5.33 & 4.98 & 5.50 & 5.14 & 6.60 & 5.26 & 5.84 & 5.37 & 5.25 & 5.44 \\
\hline & $95 \%$ ci for mean & $148.8-150.4$ & $148.1-150.1$ & $149.8-152.3$ & $150.7-153.0$ & $148.0-151.0$ & $147.6-151.6$ & $149.4-151.0$ & $149.4-151.0$ & $147.9-150.2$ & $149.5-150.4$ \\
\hline \multirow{3}{*}{$\begin{array}{l}\text { Weight } \\
(\mathrm{kg})\end{array}$} & mean & 45.62 & 44.31 & 45.95 & 47.95 & 44.56 & 44.17 & 45.41 & 46.18 & 44.93 & 45.51 \\
\hline & $\mathrm{sd}$ & 7.11 & 5.96 & 8.23 & 6.71 & 7.82 & 4.86 & 6.56 & 8.08 & 7.68 & 7.21 \\
\hline & $95 \%$ ci for mean & $44.6-46.6$ & $43.1-45.5$ & $44.1-47.8$ & $46.1-49.8$ & $42.8-46.4$ & $42.3-46.0$ & $44.5-46.3$ & $45.0-47.4$ & $43.2-46.6$ & $44.9-46.1$ \\
\hline \multirow{3}{*}{$\begin{array}{l}\text { BMI } \\
\left(\mathrm{kg} / \mathrm{m}^{2}\right)\end{array}$} & mean & 20.35 & 19.89 & 19.90 & 20.76 & 19.92 & 19.71 & 20.11 & 20.11 & 20.17 & 20.2 \\
\hline & sd & 2.77 & 2.25 & 3.08 & 2.97 & 3.15 & 1.71 & 2.56 & 2.56 & 3.04 & 2.81 \\
\hline & $95 \%$ ci for mean & $20.0-20.7$ & $19.4-20.3$ & $19.2-20.6$ & $20.0-21.6$ & $19.2-20.6$ & $19.1-20.4$ & $19.8-20.5$ & $19.7-20.5$ & $19.5-20.8$ & $20.0-20.4$ \\
\hline \multirow{3}{*}{$\begin{array}{l}\text { MUAC * } \\
(\mathbf{c m})\end{array}$} & mean & 23.35 & 23.33 & 23.50 & 24.52 & 23.19 & 23.14 & 23.36 & 23.65 & 23.54 & 23.47 \\
\hline & sd & 2.66 & 2.21 & 2.69 & 2.77 & 2.65 & 1.80 & 2.43 & 2.93 & 2.64 & 2.61 \\
\hline & $95 \%$ ci for mean & $23.0-23.7$ & $22.9-23.8$ & $22.9-24.1$ & $23.8-25.3$ & $22.6-23.8$ & $22.5-23.8$ & $23.0-23.7$ & $23.2-24.1$ & $23.0-24.1$ & $23.2-23.7$ \\
\hline \multirow{4}{*}{$\begin{array}{l}\text { Haemoglobin } \\
(\mathrm{g} / \mathrm{dL})\end{array}$} & $\mathbf{n}$ & 189 & 99 & 80 & 55 & 75 & 29 & 213 & 172 & 81 & 498 \\
\hline & mean & 12.38 & 12.81 & 12.31 & 12.46 & 12.45 & 12.26 & 12.59 & 12.44 & 12.30 & 12.49 \\
\hline & sd & 1.99 & 1.97 & 1.78 & 1.74 & 1.86 & 1.85 & 1.88 & 1.78 & 2.06 & 1.86 \\
\hline & $95 \%$ ci for mean & $12.1-12.7$ & $12.4-13.2$ & $11.9-12.7$ & $12.0-12.9$ & $12.0-12.9$ & $11.6-13.0$ & $12.3-12.8$ & $12.2-12.7$ & $11.8-12.8$ & $12.3-12.7$ \\
\hline
\end{tabular}

* in this group, there were 190 Tamang women and a total of 499. 
of which were Kami (30) and Praja (11). 76.2\% of women had received no formal schooling, although $21.6 \%$ said that they could read. Only $10.6 \%$ of women had progressed to secondary school. As expected, the vast majority of women $(88.0 \%)$ were engaged in a combination of housework and agriculture. This was less likely to be the case for Newar women, who reported greater employment in business $(20.0 \%)$ or waged labour $(5.5 \%)$. This was also more likely to be the case for women from the other group.

Primary results for height, weight, BMI, MUAC and blood haemoglobin are presented in Table 1, stratified by ethnic group and by age group. There was one missing value for MUAC and three missing values for maternal age. The distributions of all the variables approximated to normality. Mean height was $149.9 \mathrm{~cm}$ (95\% confidence interval for mean $149.5-150.4 \mathrm{~cm}$ ); mean weight was $45.5 \mathrm{~kg}$ (95\% CI 44.9 - $46.1 \mathrm{Kg})$; mean BMI was $20.2 \mathrm{~kg} / \mathrm{m}^{2}\left(95 \%\right.$ CI $\left.20.0-20.4 \mathrm{~kg} / \mathrm{m}^{2}\right)$; mean MUAC was $23.47 \mathrm{~cm}(95 \%$ CI $23.2-23.7 \mathrm{~cm})$. Newar women were statistically more likely to be taller than Magar and Tamang women, and more likely to be heavier than Magar women. There were no statistical differences between BMIs, however, in the different ethnic groups. There was a trend to greater MUAC in Newar women, this difference attaining significance in comparison with Tamang women. Although there was a trend towards lower height, weight, BMI and MUAC in women under the age of 20 , this did not attain significance.

Two blood haemoglobin measurements could not be made. Mean blood haemoglobin level was 12.5 $\mathrm{g} / \mathrm{dL}(95 \%$ CI 12.3 - $12.7 \mathrm{~g} / \mathrm{dL})$. No significant differences were noted between either ethnic or age groups.

Table 2 presents the secondary classification of BMI, MUAC and anaemia stratified by ethnic group and by age group. Overall, $27.8 \%$ (95\% CI $24.1-32.2 \%$ ) of women showed evidence of CED on the basis of BMI, and 51.5\% (95\% CI $47.0-$ $56.0 \%$ ), on the basis of MUAC. Grade 3 CED was seen in $4.2 \%$ of women on the basis of BMI and $19.0 \%$ on the basis of MUAC. There were no significant differences in BMI or MUAC between either ethnic or age groups. $35.3 \%$ of women were anaemic (95\% CI 31.1 - 39.7\%), one percent severely so. Despite an arguably greater tendency to anaemia in Brahmin/Chhetri women, there were no significant differences in prevalence between ethnic groups. The relationship between age and anaemia was examined. There were no significant age group differences in the prevalence of anaemia on basic analysis, and there was an insignificant relationship between age and blood haemoglobin level in a linear regression model. However, logistic regression of age on anaemia (coded as present or absent) suggested an association that was significant at the five percent level $(\mathrm{p}=0.02)$. We examined the relationship between anaemia and BMI. There was no clear relationship between low BMI and the presence of anaemia (Pearson chi square statistic $0.89, \mathrm{p}=0.35$ ), and $\mathrm{BMI}$ is therefore not a good candidate for anaemia screening.

Questions were asked about menstrual regularity, duration and use of pads. The duration of regular menstruation (in days) followed a J-shaped distribution, as did the number of pads used per day. The median menstrual duration was 4.5 days (interquartile range $3-6$ days) and the median number of pads used per day was 2 (interquartile range 1-3). Only $64 \%$ of women were experiencing a regular cycle. Among those whose cycles were irregular - or who were amenorrhoeic - the major cause was the use of contraception (50.3\%). Lactational amenorrhoea (19.6\%) and menopause $(8.9 \%)$ were also common, but it was notable that in $18.4 \%$ of cases the menstrual irregularity could not be easily explained. Overall, $58.2 \%$ of women 
Table 2 : BMI, MUAC and anaemia ranges in the sample, stratified by ethinic group and age group.

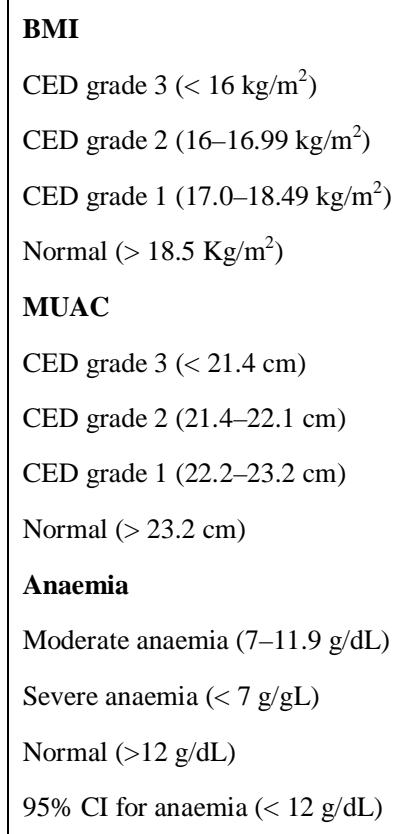

\section{Ethnic group}

\begin{tabular}{|c|c|c|c|c|c|c|c|c|c|}
\hline Tamang & Magar & $\begin{array}{l}\text { Brahmin } \\
\text { Chhetri }\end{array}$ & Newar & Other & $<20$ & $20-29$ & 30-39 & 40- & \\
\hline Freq $(\%)$ & Freq $(\%)$ & Freq $(\%)$ & Freq $(\%)$ & Freq $(\%)$ & Freq $(\%)$ & Freq $(\%)$ & Freq $(\%)$ & Freq (\%) & Freq $(\%)$ \\
\hline $8(4.19)$ & $2(2.02)$ & $5(6.25)$ & $1(1.82)$ & $5(6.67)$ & $0(0.00)$ & $7(3.27)$ & $8(4.62)$ & $6(7.41)$ & $21(4.23)$ \\
\hline $13(6.81)$ & $4(4.04)$ & $6(7.50)$ & $5(9.09)$ & $8(10.67)$ & $1(3.45)$ & $16(7.48)$ & $14(8.09)$ & $5(6.17)$ & $36(7.20)$ \\
\hline $22(11.52)$ & $22(22.22)$ & $18(22.50)$ & $6(10.91)$ & $15(20.00)$ & $5(17.24)$ & 34 (15.89) & $28(16.18)$ & 15 (18.52) & $83(16.60)$ \\
\hline 148 (77.49) & 71 (71.72) & $51(63.75)$ & 43 (78.18) & 47 (62.67) & $23(79.31)$ & $157(73.36)$ & $123(71.10)$ & $55(67.90)$ & $360(72.20)$ \\
\hline $41(21.58)$ & 17 (17.17) & $14(17.50)$ & 7 (12.73) & $16(21.33)$ & $5(17.24)$ & 40 (18.78) & 33 (19.08) & 17 (20.99) & $95(19.04)$ \\
\hline $18(9.47)$ & 15 (15.15) & $9(11.25)$ & $3(5.45)$ & 14 (18.67) & 4 (13.79) & $26(12.21)$ & $23(13.29)$ & $5(6.17)$ & $59(11.82)$ \\
\hline $41(21.58)$ & $23(23.23)$ & $12(15.00)$ & $14(25.45)$ & 13 (17.33) & $8(27.59)$ & $48(22.54)$ & $26(15.03)$ & $20(24.69)$ & $103(20.64)$ \\
\hline $90(47.37)$ & 44 (44.44) & $45(56.25)$ & $31(56.36)$ & $32(42.67)$ & $12(41.38)$ & 99 (46.48) & $91(52.60)$ & 39 (48.15) & $242(48.50)$ \\
\hline $67(35.45)$ & $31(31.31)$ & 33 (41.25) & $18(32.73)$ & $22(29.33)$ & 7 (24.14) & $63(29.58)$ & 65 (37.79) & $35(43.21)$ & $171(34.34)$ \\
\hline $2(1.06)$ & $1(1.01)$ & $0(0.00)$ & $0(0.00)$ & $2(2.67)$ & $1(3.45)$ & $2(0.94)$ & $1(0.58)$ & $1(1.23)$ & $5(1.00)$ \\
\hline $120(63.49)$ & 67 (67.68) & 47 (58.75) & 37 (67.27) & $51(68.00)$ & $21(72.41)$ & $148(69.48)$ & $106(61.63)$ & $45(55.56)$ & $322(64.66)$ \\
\hline $29.6-43.8$ & $23.3-42.5$ & $30.4-52.8$ & $20.7-46.7$ & $21.7-43.8$ & $12.7-47.2$ & $24.4-37.2$ & $31.1-46.1$ & $33.4-55.9$ & $31.1-39.7$ \\
\hline
\end{tabular}


reported the use of some method of family planning. The differences between ethnic groups were not significant, but those between age groups were. A logistic regression of age on family planning (coded yes or no) achieved significance at the five percent level ( $p=0.003$ ): increasing age was associated with an increase in use of contraception. The commonest method in use was Depo Provera (50.5\%), followed by permanent methods: tubal ligation for women and vasectomy for their husbands. Interestingly, condom use was not reported as a form of contraception.

\section{DISCUSSION}

Low levels of education and literacy are confirmed by the study: about $45 \%$ of women had either attended school or said that they could read. One in ten women had progressed to secondary school. Although most women were involved in agriculture (88\%), their husbands were slightly more likely to be engaged in business, waged employment or service occupations, with a preponderance in the Newar and other groups. This probably reflects the role of the husband as primary breadwinner within the family, and a role for women in the agricultural work that most families in Makwanpur undertake.

The study suggests that about $28 \%$ of MWRA in the area in question have CED on the basis of BMI, (52\% on the basis of MUAC). The BMI findings accord well with the results of the Nepal Family Health Survey 1996 (NFHS), ${ }^{1}$ which documented a mean BMI of $19.8 \mathrm{~kg} / \mathrm{m}^{2}$ and a prevalence of low

Table 3: Other studies of nutritional status and anaemia in Nepal.

\begin{tabular}{|c|c|c|c|c|c|c|}
\hline Source & $\begin{array}{c}\text { Year of } \\
\text { publication }\end{array}$ & Location & Sample & $\begin{array}{c}\text { Anaemia } \\
(\%)\end{array}$ & $\begin{array}{c}\text { Low } \\
\text { MUAC } \\
(\%)\end{array}$ & $\begin{array}{c}\text { Low } \\
\text { BMI } \\
(\%)\end{array}$ \\
\hline MIRA & 2001 & Makwanpur District & 500 & $35.3^{\text {(a) }}$ & $51.5^{(\mathrm{e})}$ & $27.8^{\text {(h) }}$ \\
\hline NFHS 1 & 1996 & National & 3217 & & & $28.3^{(\mathrm{h})}$ \\
\hline Patan Hospital 10 & 2000 & Lalitpur & 2280 pregnant & $62.2^{(\mathrm{b})}$ & & \\
\hline UMN 11 & 2000 & Jumla District & 105 & & $62.9^{(\mathrm{f})}$ & $21.8^{(\mathrm{h})}$ \\
\hline NNIPS 12 & 1999 & Sarlahi District & 1936 & & $88.6^{(\mathrm{g})}$ & \\
\hline UMN 13 & 1999 & Salyan District & 210 & & $67.6^{(\mathrm{f})}$ & \\
\hline NMSS 6 & 1998 & National & About 14000 & $66.7^{\text {(a) }}$ & & $26.3^{(\mathrm{h})}$ \\
\hline NNIPS 14 & 1997 & Sarlahi District & $\begin{array}{l}968 \text { pregnant } \\
611 \text { lactating }\end{array}$ & $\begin{array}{l}70.6^{\text {(c) }} \\
81.5^{\text {(a) }}\end{array}$ & & \\
\hline UMN 15 & 1997 & Dailekh District & 213 & & $80.3^{(\mathrm{f})}$ & \\
\hline Prasuti Griha 16 & 1995 & Kathmandu & 300 adolescents & $17.3^{(\mathrm{d})}$ & & \\
\hline SCF 17 & 1982 & Surkhet & Not stated & $72.0^{(\mathrm{c})}$ & & \\
\hline
\end{tabular}

NFHS: Nepal Family Health Survey 1996. UMN: United Missions to Nepal. SCF: Save the Children Fund. NNIPS: Nepal Nutrition Intervention Project, Sarlahi. NMSS: Nepal Micronutrient Status Survey 1998.

(a) defined as haemoglobin $<12 \mathrm{~g} / \mathrm{dl}$.

(b) defined as haematocrit $<34 \%$ in the first and third trimesters, or $<33 \%$ in the second trimester.

(c) defined as haemoglobin $<11 \mathrm{~g} / \mathrm{dL}$.

(d) defined as haemoglobin $<10 \mathrm{~g} / \mathrm{dL}$..

(e) defined as $<23.3 \mathrm{~cm}$.

(f) defined as $<23.6 \mathrm{~cm}$.

(g) defined as $<24 \mathrm{~cm}$. 75\% of MUACs were below the fifth centile for American women.

(h) defined as $<18.5 \mathrm{~kg} / \mathrm{m} 2$.

(g) defined as haemoglobin $<11 \mathrm{~g} / \mathrm{dl}$. 
BMI of 28.3\%, and the Nepal Micronutrient Status Survey 1998, which documented a prevalence of low BMI of $26.3 \% .^{6} 16.0 \%$ of women had heights of less than $145 \mathrm{~cm}(80 / 500)$ : the corresponding result from the NFHS was $14.8 \%$. Table 3 summarises the findings of similar studies from Nepal. The anthropometric results accord reasonably well. The relevant WHO guideline is that a prevalence of above $20 \%$ constitutes a serious public health problem.

The relationship between the recommended ranges of MUAC and those of BMI was not useful. It is possible that the correlative ranges for the two variables are not appropriate in this population. As a pilot procedure, we attempted to define a range of MUAC that would correspond more accurately in future work in the locality. We therefore generated sensitivities and specificities across a range of cut-off points for MUAC, taking BMI as the gold standard. These values were plotted as a receiver-operator characteristic (ROC) curve to locate the most useful cut-off point in terms of a combination of sensitivity and specificity. If CED is assumed to exist at BMI levels of less than 18.5 $\mathrm{kg} / \mathrm{m}^{2}$, we propose a MUAC cut-off point of 21.5 $\mathrm{cm}$ (less than $21.5 \mathrm{~cm}$ suggests CED, greater than or equal to $21.5 \mathrm{~cm}$ suggests normality). This new range has a sensitivity of 0.84 , a specificity of 0.86 and a positive predictive value of 0.70 for CED on the basis of BMI. We propose to validate this pilot range in a larger sample within the study area.

Anaemia remains a major public health problem. WHO estimates suggest that about $56 \%$ of women in developing countries are anaemic: ${ }^{7} 16 \%$ of maternal deaths in India may be attributable to anaemia. ${ }^{8}$ The aetiology is in most cases iron deficiency, and it has been emphasised that pregnant women should receive iron and folic acid supplements daily for at least six months, as well as consideration for treatment of hookworm (and, in endemic areas, of malaria). ${ }^{9}$
The present study shows limited concordance with other estimates of the prevalence of anaemia (see Table 3). The mean haemoglobin level in the present study was $12.5 \mathrm{~g} / \mathrm{dL}$, with a rate of anaemia of $35 \%$. Unfortunately, there is a lack of homogeneity in the literature as regards classification. Some studies use lower cut-off points for the definition of anaemia, such as $10 \mathrm{~g} / \mathrm{dL}$, and there is also the issue of pregnancy and nonpregnancy. In general, there is agreement that anaemia be defined as $<12 \mathrm{~g} / \mathrm{dL}$ in the nonpregnant state and $<11 \mathrm{~g} / \mathrm{dL}$ in pregnancy. Nevertheless, there is considerable difference between our estimate of $35 \%$ and the NNIPS estimate of $81.5 \%$ in lactating women. This difference is also manifest in recent data from a national micronutrient status survey, ${ }^{6}$ which suggest a rate of about $67 \%$ nationally, with slightly lower rates in Hill regions and higher rates in the Terai. Although the Terai figures in general would be expected to be higher than those found in the present study, there remains a discrepancy.

There are two possible explanations for the lower prevalence of anaemia found in our study. First, that the sample reflects a general improvement in wellbeing in the locality, so that levels of anaemia are lower than previously recorded. Second, that the results do not fully reflect the situation within the population of Makwanpur District as a whole. The sampling, though carried out at a number of sites, was not randomised, and this may have biased the results upward. Further, the sampling process was stratified for the main ethnic groups, and there may be clustering of poorer results among other ethnic groups (such as Praja and occupational groups) who are more socioeconomically disadvantaged

Menstrual irregularity was common in women in the study (36\%), primarily because of the use of contraceptives. This was partly the result of the relatively high levels of family planning in the 
sample. Again, this could be explained either by good service provision and uptake within the locality, or by an upward bias in the sample as a result of its cluster points. It is conceivable that women who were enrolled at health posts, for example, would be more likely to have made use of family planning services.

The study supports the assertion that macro- and micronutrient malnutrition are common in women in the district. This situation is likely to be exacerbated by pregnancy. From the point of view of potential interventions, dietary improvement might be expected to have beneficial effects on newborn infant outcome. Such improvement, however, may be difficult to achieve within the economic limitations and cultural situation of women in the study area. Another more pragmatic intervention might be to attempt to alleviate the anaemia problem by ensuring adequate provision of recommended iron and folate supplements for pregnant women. Although we did not quantify hookworm infestation, deworming may also be helpful in the prevention of anaemia.

\section{CONCLUSIONS}

The prevalences of chronic energy deficiency and anaemia are high in Makwanpur District. As part of a package to improve newborn infant outcome, access to and uptake of haematinics during pregnancy should be beneficial. Community level intervention needs to attempt to address the issue of food intake in young girls and women before improvements in nutritional status are possible.

\section{ACKNOWLEDGEMENTS}

The MIRA Makwanpur Study receives funding from the Department for International Development
(DFID), UK, from the World Health Organization (WHO), Geneva and from UNICEF, Nepal.

\section{REFERENCES}

1. Pradhan A, Aryal R, Regmi G, Ban B, Govindasamy P. Nepal Family Health Survey 1996. Kathmandu: Ministry of Health, Nepal; New ERA; Macro Intemational Inc., 1997.

2. Nepal Research Associates. Makwanpur District Profile: District Development Committee, 1999.

3. James W, Ferro-Luzzi A, Waterlow J. Definition of chronic energy deficiency in adults. Report of a working party of the International Dietary Energy Consultative Group. European Joumal of Clinical Nutrition 1988;42:969-81.

4. Ferro-Luzzi A, et al. A simplified approach of assessing adult chronic energy deficiency. European Journal of Clinical Nutrition $1992 ; 46: 173-86$.

5. WHO Expert Committee on Physical Status. Physical status: the use and interpretation of anthropometry: Report of a WHO expert committee. WHO Technical Report Series:854. Geneva: WHO, 1995.

6. Nepal Micronutrient Status Survey 1998. Kathmandu: Nepal: Ministry of Health, Child Health Division, HMG/N, New Era, Micronutrient Initiative, UNICEF Nepal, WHO, 1998.

7. WHO. The prevalence of anaemia in women: a tabulation of available information. Geneva: WHO/ $\mathrm{MCH} / \mathrm{MSM} / 92.2,1992$.

8. Abou Zahr C, Royston E. Maternal mortality. A global factbook. Geneva: WHO, 1991.

9. Stoltzfus R, Dreyfuss M. Guidelines for the use of iron supplements to prevent and treat iron deficiency anemia. Washington: INACG/WHO/ UNICEF: IISI Press, 1998.

10. Bondevik G, Ulstein M, Lie R, Rana G, Kvale G. The prevalence of anemia in pregnant Nepali women: a study in Kathmandu. Acta Obstetrica et Gynecologica Scandinavica 2000; 79:341-9. 
11. Shakya S. Nutritional status of the women of reprocuctive age and children under 5 years in the areas covered by Chhumchaur, Patarasi and Guthichaur Village Development Committees in Jumla. A baseline survey report. Kathmandu: Nutrition Programme, United Mission to Nepal, 2000 .

12. Pradhan E, LeClerq $S$, Khatry $S$, Adhikari R, Ram $R$, West $K$, et al. A window to child health in the Terai. Kathmandu: NNIPS Monograph No.1, 1999.

13. Sinha A. Understanding UMN's nutrition work and achievements in Salyan District, 1995-1999. Kathmandu: Nutrition Programme, United Mission to Nepal, 1999.
14. Dreyfuss M, Shrestha J, Khatry S, Shrestha S, Dali $S$, Adhikari R, et al. The prevalence of anaemia among pregnant and lactating women, and among their infants in Sarlahi District. Joumal of the Nepal Medical Association 1997; 35:234-40.

15. Sinha A. Understanding the nutritional status of the areas covered by six VDCs of Dailekh District. Kathmandu: Nutrition Programme, United Missions to Nepal, 1997.

16. Tuladhar H. Anaemia in adolescent pregnancy. Nepal Medical College Journal 2000;2:19-21.

17. Cutts F, Quinlisk P. Surkhet District anaemia survey. Journal of the Institute of Medicine $1982 ; 4: 13-24$.

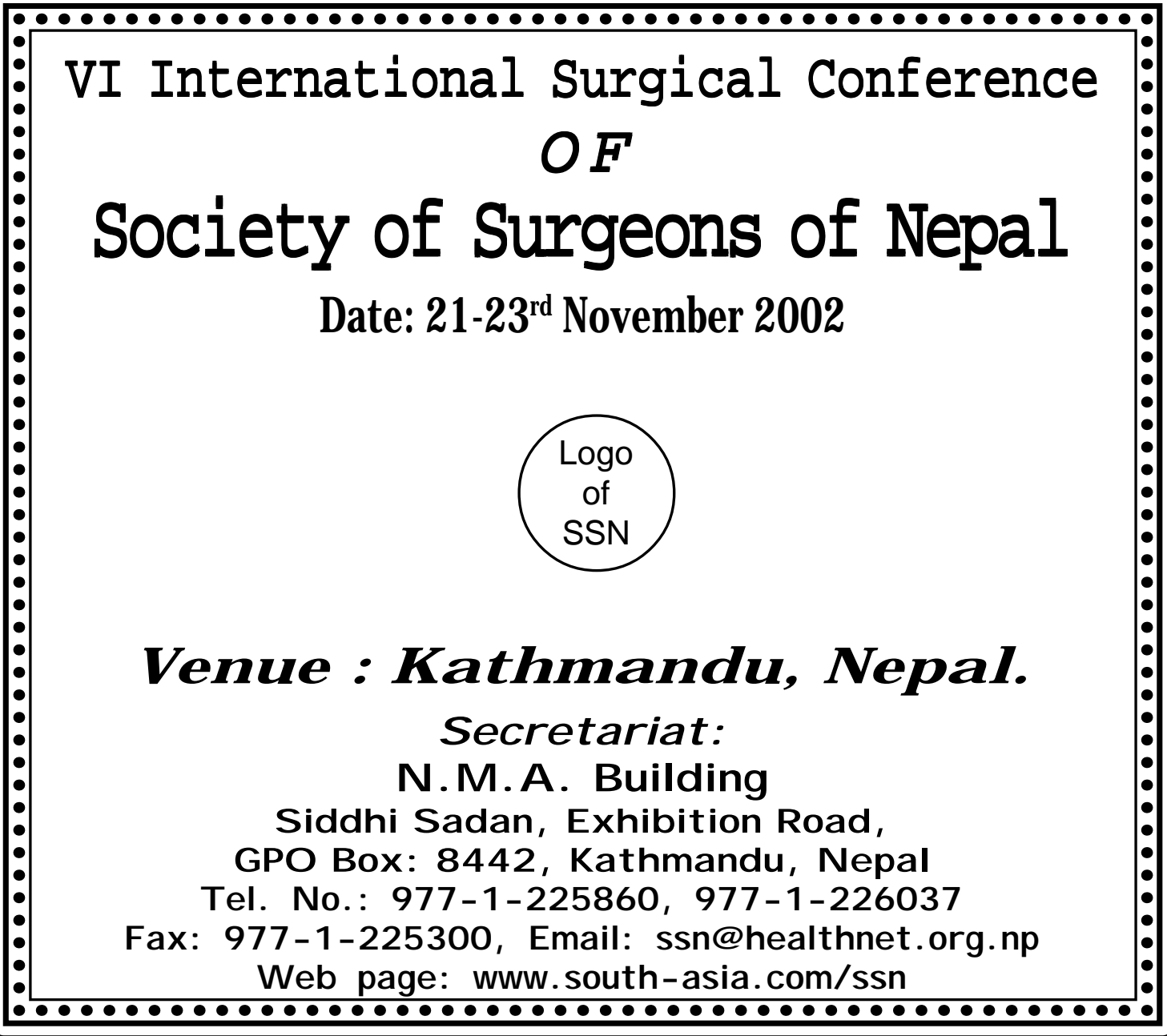

JNMA, October - December, 2001, 40 